\title{
Information systems in developing countries: a critical research review
}

\section{Chrisanthi Avgerou}

\author{
Department of Information Systems, London School of Economics \& Political Science, London, UK \\ Correspondence: Chrisanthi Avgerou, Department of Information Systems, London School of Economics \& Political \\ Science, Houghton Street, London WC2A 2AE, UK. \\ Tel: + 440207955 7634; \\ Fax: + 440207955 7385; \\ E-mail: C.Avgerou@lse.ac.uk
}

\begin{abstract}
In this paper I review the Information Systems (IS) research on how developing countries have attempted to benefit from information and communication technologies (ICTs). First I identify three discourses on IS implementation and associated organizational and social change that coexist in information systems in developing countries (ISDC) research, namely as a process of technology and knowledge transfer and adaptation to local social conditions; as a process of socially embedded action; and as a process of transformative techno-organizational intervention associated with global politics and economics. I then point out the distinctive research agenda that has been formed in ISDC studies, both in the more familiar IS themes - failure, outsourcing, and strategic value of ICT - and also in studies of themes relevant specifically to the context of developing countries, such as the development of community ICT and information resources. Finally, I call the reader's attention to the potentially significant theoretical contributions of ISDC research for understanding IS innovation in relation to social context and in relation to socio-economic development theories and policies.
\end{abstract}

Journal of Information Technology (2008) 23, 133-146 doi:10.1057/palgrave.jit.2000136

Published online 17 June 2008

Keywords: developing countries; information systems; innovation; development; discourses

\section{Introduction}

T he pace and direction of information and communication technology (ICT) innovation and concomitant organizational change, which comprise the object of study of the information systems (IS) field, are undoubtedly set by the advanced economies of the world, primarily in North America and Europe. Nevertheless, the international IS literature includes an increasing number of studies of IS innovation experiences in other regions of the world, mainly the developing countries of Asia, Africa, and Latin America. Such studies considerably expand the empirical basis that informs IS research findings. More significantly they expand the domain of research of the IS field by addressing new themes, such as the provision of ICT resources for a community (Reilly and Gomez, 2001; Madon, 2005), and by highlighting dimensions of the process of IS innovation that so far have received relatively little attention in mainstream IS research, such as national culture (Sahay, 1998) or global politics (Ciborra, 2005).

Most research concerning IS innovation in developing countries is published in specialist conferences and journals. A valuable literature resource has been formed by the proceedings of the series of conferences on ICT in developing countries organized by the IFIP WG9.4, published in books and journal special issues (Bhatnagar and Bjørn-Andersen, 1990; Bhatnagar and Odedra, 1992; Odedra-Straub, 1996; Roche and Blaine, 1996; Avgerou and Walsham, 2000; Krishna and Madon, 2002; Sahay and Avgerou, 2002; Krishna and Madon, 2003). The journals Information Technology for Development, Information Technologies and International Development, and the Electronic Journal of Information Systems in Developing Countries (EJISDC) are dedicated to this area of research, and the Journal of Global Information Technology Management frequently publishes papers on developing countries. Increasingly general IS conferences acknowledge this research subfield and include panel and paper sessions on developing countries, often within tracks on the theme of globalization. Similarly, general IS journals occasionally publish papers on research in developing countries and some of them have produced special issues in this area. ${ }^{1}$

Nevertheless the research stream of information systems in developing countries (ISDC), the nature of its research 
concerns and ongoing debates are poorly understood beyond a circle of specialists. Reviewers of IS journals require ISDC authors to justify their research questions in relation to the IS literature and compare their findings with general IS knowledge. These are valid requirements for the creation of links between what is commonly known in a research field and the particularities of its subfields. However, some understanding of the research in developing countries by the wider IS research community is necessary in order to proceed from basic to more elaborate and in-depth research accounts of IS phenomena not only in developing countries but also in the world at large in the era of globalization. As IS transcend organizational and national boundaries and support global economic and political activities, knowledge of the conditions and the processes of socio-technical change in developing countries acquires general significance for IS research and practice.

My aim in this article is to contribute towards an understanding of the nature, contributions, and potential of the ongoing research on IS in developing countries. Having the general IS scholars and practitioners in mind, I review the ISDC research in juxtaposition to the collective IS research and its general body of knowledge. My task, therefore, in this paper is different from reviews intended to guide researchers in the subfield, such as Sahay and Walsham (1995) and Walsham and Sahay (2006a). While I comment on epistemological approaches in the subfield, my main objective is to inform the broader IS research community on substantive ISDC research concerns and contributions.

I have taken an interest in ISDC research ever since its emergence in the late 1980s and followed its shaping closely ever since. Therefore I started writing this review with an 'insider's' confidence of understanding the unfolding of this research area and its literature. As an interpretivist researcher my effort aims to present the way I make sense of ISDC research, and to substantiate the validity of my descriptions and arguments with references to and discussion of its body of literature. I have taken care to avoid two pitfalls: vulgar eclecticism and 'inbreeding'. The former concerns the ad hoc selection of ideas - lifting them out of epistemologically cohesive theoretical steams that gave rise to them - and their loose combination as a 'body' of knowledge. The latter refers to focusing too narrowly on the work of a small number of researchers with whom I am similarly minded, in a self-referential way, that is, without positioning their research arguments within the broader and more diverse opinions of the ISDC field. To that end, although the initial impetus for doing this review stemmed from my existing knowledge of the field, the crafting of the presentation of the field in terms of the categories of research I discuss, the contributions I highlight, and my arguments of their significance and limitations, necessitated an almost exhaustive reading - with a large amount of re-reading - of articles and chapters in the sources I identified above as its publication outlets.

I have excluded from this review publications that present particular technologies or IS innovation initiatives in developing countries, or case studies elaborating on the experience of an organization or country without attempting to form and substantiate theoretically analytical claims about the nature of the narrated experience. There is a lot of such literature in ISDC, providing a useful source of information on the kind of innovation taking place in developing countries and the challenges faced by practitioners, but it plays a marginal role in the analysis of the academic subfield that I am undertaking here.

Throughout this paper I use the term 'IS innovation' to refer to the development and implementation of ICT systems and concomitant organizational change. That IS implementation comprises technology development and organizational change does not require explanation for the readers of an IS journal. But it is, perhaps, somewhat unusual in the IS literature to see such socio-technical change as 'innovation'. I chose this term to convey the notion of novelty and open-endedness of the effort and experience of IS implementation and of the associated changes within the hosting organization and beyond it. Even if the technologies implemented in an IS project are common and widespread, the local IS implementation experience constitutes an innovation for the organization undertaking it and may well constitute innovation for its socio-economic context.

The paper is structured as follows. In the next section, I present three discernible discourses in ISDC research. The first one considers IS innovation in terms of transferring ICT and organizational practices from advanced economies and adapting them to the context of particular developing countries. The second discourse considers IS innovation as a process embedded in local conditions of a developing country. The third discourse addresses IS innovation as a transformative intervention and associates it with aspirations and policies for socio-economic development. I use examples from the ISDC literature on IS implementation and organizational change to clarify these three discourses. In the following section I discuss ISDC research in terms of the distinctiveness of its research agenda, examining the themes and issues it addresses. I discuss the main issues addressed in studies of some of the common themes of the IS research, namely on IS failure, on outsourcing, and on the strategic value of IS innovation. Also I discuss the research on telecentres, as a topic that emerged in the context of developing countries. I then discuss the potential of new theory building in ISDC research. I discern such potential in contextual analyses of IS innovation, and in studies of the developmental role of ICT within alternative socio-economic development policies. Finally, in Conclusions, I comment on the contributions of ISDC research, pointing out the new intellectual ground the transformative ISDC discourse is opening for the IS field.

\section{An overview of discourses in the ISDC literature}

A concern that permeates the ISDC literature is the condition of severely limited financial resources, technology, and skills in most developing countries or regions. Some research, such as that on the digital divide or on the extent of ICT diffusion, focuses explicitly on the lack or limited availability of technology, and argues about the significance of this problem or monitors progress in reducing it (Wresch, 1998; Kenny, 2000; Mbarika et al., 2003).

Nevertheless, in the nearly 20 years period of ISDC research $^{2}$ an increasing amount of resources has been dedicated to ICT even in the poorest countries, whether through local and multinational business investment, or 
channels of international development aid. There has therefore been a long and continuous effort of engagement with IS development and management in all organizational fields of developing countries, and it is the challenges of such efforts that most ISDC research has been addressing. ${ }^{3}$ Thus, by and large, ISDC research focuses on the experiences and consequences of IS innovation rather than the resource limitations that inhibit it. For this task, ISDC studies draw heavily from the theories and epistemologies of the IS field. But they also depart from them in response to the perceived particularities of the IS innovation endeavours in developing countries, and as a result they form distinctive discourses.

I use the term discourse here to refer to a combination of assumptions on the nature of the IS innovation processes in developing countries and relevant conceptual constructs in the study of these processes. My discussion of the ISDC literature through the notion of discourse is based on the epistemological position that the research language is part of the constitution of the object of a research study as well as the arguments formed about it. In effect, these assumptions and constructs of the ISDC research field form particular ways of representing (a) what IS innovation in developing countries is primarily for, and (b) what kind of effort it involves.

I identify three salient discourses in the ISDC literature. The first discourse is rooted on the assumption that IS innovation in developing countries is mainly concerned with catching up with the technologically advanced rich economies through transferring their technologies and emulating their institutions. It examines IS innovation as the diffusion of IS knowledge transferred from advanced economies and adapted to the conditions of developing countries. The second discourse assumes that IS innovation in developing countries is about constructing new technoorganizational structures within a given local social context and places research emphasis on exploring local meanings and working out locally appropriate techno-organizational change. It thus focuses attention on the social embeddedness of IS innovation in the context of developing countries. The third discourse takes IS innovation to be primarily concerned with creating possibilities for the improvement of life conditions in a particular locality amidst the global socio-economic order and is interested in the processes through which IS innovation leverages large-scale and deep socio-economic change. It therefore considers IS innovation as a transformative socio-economic process.

These three discourses are discernible in the literature of all ISDC research themes, but for purposes of clarification in this section I draw examples from studies on IS development and implementation. Authors engaging with the transfer and diffusion discourse assume and endeavour to show the relevance of general IS research knowledge and good practice models (methods, analytical approaches, or theories) in particular developing countries or regions and to work out adaptations appropriate for them. They often shape their research in the conceptual terms of the theories of technology diffusion and technology acceptance (Davis, 1989; Rogers, 1995). For example Rose and Straub (1998) and Al-Gahtani (2003) used Davis' technology acceptance model to study IT use in the Arab world, thus empirically identifying the particular factors of the social and organizational context of the Arab countries that affect their take up of ICT (Rose and Straub, 1998; Al-Gahtani, 2003).

Many studies have sought to transfer and adapt systems development methodologies to accommodate analyses of the socio-organizational conditions of developing countries (Bell and Wood-Harper, 1990; Korpela, 1996a; Korpela et al., 2000; Mursu et al., 2003). Similar method adaptation efforts have addressed the implementation of ERP technologies and IS-driven organizational change (Jarvenpaa and Leidner, 1998; He, 2004). Such studies enrich IS implementation knowledge and professional practice by working out modifications appropriate to accommodate various local circumstances. They shift the IS discourse on systems development from an a-contextual 'best practice' towards a notion of 'appropriate', context-specific practice (Avgerou and Land, 1992; Bada, 2002). In effect, they challenge the feasibility of 'transferring' generic technical know-how into developing countries organizations with the expectation that it will result in the same organizational practices and outcomes as in their context of origin (Avgerou, 1996). Yet, they retain the general assumptions on the validity of purpose of the attempted innovation as well as the validity of the underlying objectives and rationality of the transferred methods in their new context of practice.

A further shift away from a-contextual IS knowledge is made by considering ICT innovation and organizational change as socially embedded action, studied through social constructionist and situated research perspectives (Orlikowski, 1996; Ciborra and Associates, 2000). Rather than being neutral tools with generally useful functionality, technologies and techniques are understood to inscribe social preferences that have been shaped historically in the environment in which they have been developed (Akrich, 1992). Authors of the social embeddedness discourse view IS innovation as a locally socially constructed course of action. Innovation is studied as a locally constituted process of technology construction and organizational change. Its purpose arises from local problematizations and its course is determined by the way local actors make sense of it and accommodate it in their lives (Avgerou, 2002).

An example of research that takes such a socially embedded view of IS innovation is the series of publications on an extensive action research programme aiming to contribute to the development and implementation of healthcare information systems (HISP) in African, Asian, and Latin American countries (Braa et al., 2004, 2007a). Authors analysing the HISP efforts have used a variety of complementary socio-theoretical approaches - structuration, ANT, Castells networks of action model, complexity theory. They have not used a general model of principles of effective healthcare infrastructure. Instead, they have aimed to develop a conceptual analytical capacity to guide context-specific sense making and practice in countries with different healthcare systems and practices. This has led them to consider a range of issues, including standards that are sensitive to the local context and multiple country collaboration across north (technologically and economically advanced) and south (developing) regions (Braa et al., 2007a).

Another good example of the socially embeddedness discourse is a study of a 10 -year effort to implement a data 
infrastructure for land administration in Guatemala by Silva (2007). His study traced the unfolding of power dynamics within the institutional context of the country and focused on the historically formed lack of interinstitutional cooperation in the country, which created conditions unfavourable to sharing data.

The transformative ISDC discourse associates IS innovation with processes of change of the social, economic, and political conditions in developing countries. In other words it addresses the development struggle in which IS innovation is implicated. Transformative research is often based on the same theoretical underpinnings regarding social context as the social embeddedness discourse. But, while socially embedded analyses tend to take social, economic, and political relations in a DC community or the world at large as given, the transformative discourse is explicitly concerned with the way ICT is implicated in the dynamics of their change (Akpan, 2003; Kanungo, 2003).

For example, in a study of the computerization of driving licenses in Jordan, Ciborra (2005) identified a sociopolitical significance of e-government interventions, which is beyond the capacity of methodical professional practices to address and which cannot be explained in terms of local social and organizational circumstances alone. Although the declared objectives of e-government projects, such as the computerization of the issuing of driving licenses, are improvements of efficiency of citizen services, Ciborra's study showed that such an innovation stumbles upon the complex network of state government controlling mechanisms. Ciborra, drawing from Heidegger's treatise on technology, pointed out the ordering character of information technology. The order sought in this case study, he argued, does not concern only the Jordanian government, but also the world order at large. He traced the origin of the rationale of e-government in developing countries in the so-called Washington Consensus and the security interests of the US government (Ciborra, 2005), thus critically revealing a transformative logic regarding IS innovation.

Interestingly, another IS innovation study in Jordan (Al-Jaghoub and Westrup, 2003; Westrup et al., 2003) emphasized the role of the country's king as the champion for the country's computerization, loaded with symbolic and political significance for the country's development amidst the current global politico-economic conditions. Despite their difference of emphasis on domestic and foreign institutions, actors, and political forces, the Ciborra and Al-Jaghoub/Westrup studies shifted the discourse of IS development away from the general technical assumptions of IS innovation of the technology diffusion paradigm as well as from the perspective of local social embeddedness, and associated IS implementation projects with macro-level political and economic concerns.

\section{Positioning ISDC discourses in broader research approach} categories

The diffusion and the social embeddedness discourses are well identified - though not necessarily with these names in ISDC research, see for example Walsham and Sahay (2006). The transformative discourse, while I believe is discernible by the careful reader, has not attracted much attention in analyses of the field. I chose to highlight its existence because, as I explain in following sections of this paper, it raises more explicitly than other approaches strategic issues of IS innovation associated with the development struggle. Thus, I consider its potential contribution particularly important not only in the ISDC research, but also in the IS field more generally.

Research categorization in terms of discourses is not new in the social sciences, and indeed the discourses I identified above share epistemological characteristics with categories on Deetz's classification scheme of approaches to organization science (Deetz, 1996). ${ }^{4}$ Deetz analysed organization science research in terms of two dimensions of contrast. The first refers to the origin of concepts and problem statements and is identified by contrasting 'local/emergent' research conceptions with 'elite/a priori' ones. In local/ emergent approaches the researcher develops relevant concepts and knowledge in relation with the organization under study. In elite/a priori approaches the researcher applies existing conceptual constructs to the organization under study seeking to establish theoretical generality. Following these categories, the social embeddedness discourse of ISDC research can be seen as local/emergent and the transfer and diffusion discourse is elite/a priori research discourse.

The second dimension of Deetz's analysis of discourses is identified by contrasting two research orientations regarding the relation of research practices to the dominant social orientation within the organization, the research community, and wider social context: 'consensus' research approaches work within the dominant social orientation and constitute a reproductive research practice, while 'dissensus' research approaches challenge and disrupt it. What I call in this paper transformative discourse bears a strong resemblance with the research Deetz identifies as the 'dissensus' approach, that is, research which produces knowledge that challenges and disrupts the dominant 'structurings' of knowledge and social relations addressed in the research field.

The discourses identified in Deetz's analysis result from the combination of the elite/local and consensus/dissensus dimensions. Such a combination, though relevant and valid in ISDC research, does not highlight the distinguishing characteristics of the discourses I discern emerging in this research area. Both the transfer and diffusion and the social embedded discourses can be oriented either towards the preservation of dominant social order or towards its transformation. Thus, being consensus or dissensus oriented is not their distinguishing characteristic. Similarly, the distinction of elite/a priori or local/emergent perspective is not significant in the transformative ISDC discourse.

Unlike Deetz's analysis, my intention in this paper is not to produce a classification scheme to show similarities and differences in ISDC research. Rather, I am interested in highlighting the most salient epistemological assumptions and orientations in the study of IS innovation in developing countries that form the basis of its knowledge contributions. Thus, the 'consensus' orientation, which treats IS innovation in the existing socio-economic order of developing countries as 'natural and unproblematic', ${ }^{5}$ is missing from my discussion of ISDC research because I believe that 
such an orientation does not contribute to the formation of a distinctive discourse in the IS field.

\section{Familiar and new IS research themes}

Not surprisingly, the ISDC literature reflects the broad thematic categories of the IS field and has followed its unfolding of research topics and conceptual approaches. Long-standing themes of IS research such as systems development and implementation, IS management, ICT and competitive advantage, IS and organizational change, are clearly present in the ISDC literature, see for example Madon (1993), Jarvenpaa and Leidner (1998), Korpela et al. (2000) and Silva (2002). However, the issues and research questions in ISDC studies of familiar IS themes are often quite different. Another distinctive feature of ISDC research is that it has given a great deal of attention to non-business organizational settings. IS innovation in the public sector and e-government, the 'free and open' software phenomenon, and the development of community resources intended to overcome the digital divide, while marginal in the IS field, are prominent in ISDC research (Heeks and Bailur, 2006; Bailur, 2007; Byrne and Jolliffe, 2007; Madon et al., 2007; Roets et al., 2007).

In this section I demonstrate the research agenda that emerged in the ISDC subfield by elaborating on some of the issues that received attention in the ISDC studies of three familiar themes of the IS field: IS failure, outsourcing, and the strategic role of ICT. I then examine the literature on telecentres, as an exemplar of a research theme formed in ISDC studies only.

\section{Problematization of failure}

The ISDC literature manifests an acute anxiety about failure. Of course, concern about failure has been persistent within the IS field in general (Strassmann, 1985; Lyytinen and Hirschheim, 1987; Brynjolfsson and Hitt, 1993; Hitt and Brynjolfsson, 1996; Sauer, 1999). In ISDC, though, this concern is intensified partly due to additional pressures for successful IS innovation, such as high opportunity costs of investment in IT projects and a perceived urgency for 'catching up' with ICT-mediated advanced economies. It is also exacerbated by overoptimistic expectations for the developmental role of ICT. ${ }^{6}$ Nevertheless, there are many indications that, in developing countries, endemic problems hinder both the completion of IS innovation initiatives and the realization of their expected benefits.

Issues of IS failure are often discussed in connection with IS design and implementation research. Authors have sought remedies in the diffusion of methodical professional practice, adapted to accommodate the requirements of the organization and its participants (Kiely and Fitzgerald, 2005), and in adopting effective management practices (Lind, 2000; Lind et al., 2000). Yet, others have been sceptical about the effectiveness of professional IS practice, codified and institutionalized in systems developments methods, to address the particular conditions of organizations in developing countries. Heeks identified the root of the problem in the gap between the professional knowledge and practice of systems development and the actual conditions of organizational practice in developing countries (Heeks, 2002), in effect arguing for socially embedded analyses to understand the reasons and address the risk of IS failure. Indeed, numerous ISDC studies have probed into the particular social context of failed IS innovation and produced insights into what often goes wrong in ISDC. Such literature confirms the validity of Lyytinen and Hirschheim's categories of process, interaction, and expectation types of failure (Lyytinen and Hirschheim, 1987). In other words, an IS project may fail to be completed, a new IS may not be used, or it may fail to produce expected benefits. Furthermore, socially embedded ISDC studies have identified and elaborated on specific problems in each of these categories of failure that often occur in developing countries, namely scalability failure, sustainability failure, and assimilation in dysfunctional organizational processes.

Even if successful in pilot implementation, many largescale IS projects in DCs face problems of scalability, that is, they may not be extended to form fully operational IS. Difficulties of going beyond limited implementation in terms of functionality and geographic spread were identified in early efforts to create computer infrastructures in the public sector. They were to some extent explained in terms of the rigidities of centralized public sector organizations of developing countries (Avgerou, 1990; Madon, 1992; Walsham, 1992; Madon and Sahay, 1996). More recently, Sahay and Walsham addressed the problem of scaling health IS (Sahay and Walsham, 2006) by drawing ideas and arguments from the socio-technical perspective on information infrastructures (Star and Ruhleder, 1996; Monteiro, 1998). They identified the problems of increasing technological complexity, human resources capacity, waning political support, and unanticipated effects and recommended local customization and cultivation (Ciborra and Associates, 2000), rather than top down standardization and imposition of a uniform, centrally controlled, information system.

Research seeking to explain sustainability failure highlighted a variety of problematic conditions across many DC countries. IS projects are often starved from resources or lose political commitment; they are poorly maintained and, consequently, they are technologically as well as functionally degraded. This problem was recognized in early research as a syndrome of the dependence of developing countries computerization on foreign aid donors, who often neglected the development of local technological capabilities (Odedra-Straub, 1993). Consequently, ongoing research on information infrastructures across public service organizations argued for the significance of local appropriation of the IS resources. In other words, an IS needs to become adequately enmeshed with organizational practices and to secure the required financial and knowledge resources, and political commitment for its continuing cultivation and growth (Braa et al., 2004).

Finally, a great deal of attention has been given to the problem that ICT-based systems may be assimilated in dysfunctional organizational practice rather than contributing to its improvement. Analysts have stressed the significance of an organizations' capacity to pursue change (Jarvenpaa and Leidner, 1998; Lind, 2000; Volkow, 2000) and elaborated on the difficulties of ICT-mediated organizational reform in developing countries. For example, Bada 
(2002) examined critically the managerial prescriptions of good organizational practice that IS projects in developing countries often try to implement and Avgerou (2002) pointed out the institutional, historically developed, and locally meaningful organizational practices that may contest the management processes associated with IS innovation.

\section{Outsourcing}

Outsourcing has been extensively researched in IS, mainly in terms of short- and long-term benefits and risks for the client organization, and the management of the relationship between clients and vendors; see for example Lacity and Hirschheim (1993) and Lacity and Willcocks (1998). These issues are of direct relevance to organizations in developing countries, many of which rely heavily on ICT services vendors because of their limited in-house, and often incountry, IS expertise. Nevertheless, studies of outsourcing concerning DC organizations as clients are relatively rare. A few noticeable exceptions from the social embeddedness perspective enrich the literature of outsourcing with insights on power and cross-cultural relations (Barrett and Walsham, 1995; Silva, 2002, 2007).

There is, however, a prominent stream within the ISDC literature that studies outsourcing from the vendors' perspective. A number of developing countries have nurtured software and ICT services industries capable of competing at the global market, thus forming a substantial part of the 'global outsourcing' or 'offshore outsourcing' phenomenon (Carmel and Agarwal, 2002). India is the most successful country in this business, and the efforts of its software firms have been studied within the ISDC subfield since its early days nearly 20 years ago (Heeks, 1990; Sahay et al., 2003; Nicholson and Sahay, 2004).

Several ISDC studies assessed the development of competitive software production capabilities in 'emerging' software producer countries and suggested factors that account for software industry success within the global market of services and products of IS innovation (Carmel, 2003a; Adelakum, 2005). Such factors include technology and project management skills, labour costs, telecommunications infrastructures, English language skills, copyright legislation, and government industrial policy. There are also ongoing studies that assess and compare the relative advantages among developing countries competing for the lucrative markets of industrialized countries (Carmel, 2003c). For example, while India is so far considered the most successful DC software exporter, competition from China on the basis of lower salaries may erode its advantage in some important markets, such as Japan.

Studies of the DCs participation in global outsourcing from the social embeddedness perspective, which focused on the micro-societal processes that constitute the practices of global outsourcing services, highlighted the difficulties of cross-cultural collaboration and the surfacing of multiple political conflicts (Barrett and Walsham, 1995; Nicholson and Sahay, 2001) and emphasized the significance of organizational identity and the intrinsically tacit nature of the knowledge of software developers (Sahay et al., 2003; Nicholson and Sahay, 2004). For example, Nicholson and
Sahay's study of the policy efforts of the Costa Rican government to promote an export-oriented industry highlighted the implications of historically formed vested interests in the country, power structures, and attitudes towards development (Nicholson and Sahay, 2007).

Despite the assumed significance of the software industry in the economies of developing countries, the transformative discourse on this topic is limited. In general, studies of the software industry in DCs tend to focus on their capacity for export of software products and services, taking such exports to be an important source of income and of national prestige. Some comparative analyses of the software industries of major developing countries suggest that there may be trade-offs between efforts to foster an export-oriented software industry and IS innovation in domestic organizations (Carmel, 2003b; Commander, 2005). For example, although successful in exporting software products and services, India's software industry is much less successful in contributing to domestic organizations' IS innovation. In contrast, Brazil's software export is negligible, but its domestic software industry is highly innovative and dynamic, contributing to innovation across public and business sectors of the country (Zwicker et al., 2006).

Yet, little attention has been given to the software industries in developing countries regarding their service to domestic organizations and the overall development effort of the region where they are located. A panel discussion at an ISDC conference in Bangalore, in $2002^{7}$ demonstrates the prevailing view. In answering the question about the contribution of the Indian software industry to the country's industries and public administration the panellists suggested that benefits from a thriving export industry are expected to trickle down to the local economy. This is an example of non-engagement with the transformative discourse that would attempt to articulate the developmental challenges of the ICT industries in the context of developing countries.

\section{Strategic role of ICT}

Arguments about the strategic importance of ICT for the competitiveness of business organizations (Porter and Millar, 1984; Scott Morton, 1991) have been echoed in the ISDC literature (La Rovere, 1996; Jarvenpaa and Leidner, 1998; Goonatilake et al., 2000; La Rovere and Pereira, 2000; Munkvold and Tundui, 2005). Studies monitoring the diffusion of e-commerce and new business models in DCs have paralleled those in the general IS studies (Tigre, 2003; Kraemer et al., 2006). Invariably such studies argue for the significance of ICT for competitive business in global markets and point out particular efforts required to overcome shortcomings of the local business contexts in order to exploit the strategic potential of ICTs.

Nevertheless, research on ICT and business firm competitiveness is a relatively small part of a broader concern of the ISDC literature with the strategic importance of ICT - meaning its potential contribution to substantial long-term gains. The strategic potential of IS innovation in DCs tends to be discussed in macro-societal transformative terms (Cecchini and Scott, 2003; Ngwenyama et al., 2006). Two areas of such literature are distinguishable: the first is 
concerned with ICT as a strategic resource for the growth of the economy; and the second with the way ICT may contribute to the improvement of social services and institutions, such as health services and state governance.

The rationale for the role of ICT in economic growth has been advanced by multiple international agencies, see for example World Bank (1999), UNDP (2001) and Kirkman et al. (2002). Some research has sought to corroborate the argument on the economic significance of ICT for development (Ngwenyama et al., 2006; Mbarika et al., 2007). It attempted to address the concerns of sceptics, who tend to point out the pressing necessity for poor countries to provide for the basic life needs of a large part of their population, alleviate extreme poverty, and fight endemic diseases and illiteracy. Sceptics question the developmental effectiveness of national and international policy initiatives that direct resources to bridging the digital divide, arguing that these are unlikely to achieve economic growth effects because there are no human capabilities, or economic conditions for their use (Warschauer, 2003; Wade, 2004).

Nevertheless, on the whole, ISDC research tends to accept the assumption that ICT potentially contributes to economic growth. Several research avenues follow this assumption. Some research has investigated the features of the ICT-based economy in particular countries or regions (Molla, 2000); others have elaborated on the conditions under which ICT-mediated business models and practices, such as e-commerce, are diffused or IT-enabled niche industries are fostered (Davis et al., 2002).

International development agencies have also emphasized the potential of ICT to improve the performance of state institutions, the delivery of health and education services, as well as democratic participation (United Nations Development Programme, 2001). This argument was reinforced through the global 'information society' international initiatives, aiming to mobilize financial resources and voluntary sector action for overcoming the digital divide problem. ${ }^{8}$ Indeed, most ISDC research assumes, either explicitly or implicitly, that ICT can make a substantial difference in the performance of social institutions in DCs and that is where most research effort of the subfield is devoted. A range of research questions emerges from this assumption, concerning mainly, effective IS design approaches (Braa et al., 2007b) and appropriate socio-organizational interventions (Madon, 2005; Miscione, 2007). The social embeddedness discourse is the most prevalent in this research domain, in effect shifting attention from what deep and long-lasting effects ICT may have in the social institutions of developing countries to how ICT-mediated practices are formed to enable improvements of social services and governance.

\section{Telecentres}

In the 1990s widespread access to electronic services from any workplace and from home came to be taken for granted in advanced economies. Much of the IS literature, such as on IT-enabled business models, built on the assumption of universal access to the internet and availability of computers with a set of common applications. Consequently, concern was raised that the vast majority of the population in developing countries are not 'connected' and therefore 'excluded' not only from the emerging e-business opportunities but also from modern society's information channels for education and health. Poverty in many DC areas, particularly the rural regions, prohibits the diffusion of ICT and telecommunication connectivity to any extent comparable to that of advanced economies. A solution appeared to be the development of community information services, often called telecentres, equipped with computers, internet connection, as well as fax and telephone. Many initiatives to introduce telecentres in poor rural communities in DCs have been taken by international NGOs, such as the Canadian IDRC's Acacia ${ }^{9}$ programme in Africa, and by country governments. Although their services vary, most of them run software applications of local interest, such as providing information on health, agricultural product prices, educational material, or the issuing of government certificates.

ISDC researchers responded to the emergence of the telecentres phenomenon with reserved optimism (Hunt, 2001; Harris et al., 2003). Early research in the 1990s presented promising initiatives, highlighting the perceived potential of local empowerment through information and communication. Later, research indicated a more nuanced picture of some impressive cases of economic gain and social empowerment, widespread failure and closure, and increasing frustration among key actors such as the entrepreneurs who owned the telecentres, users/customers, and donors (Bailur, 2007; Madon et al., 2007).

At a first glance, the discourse of telecentres research appears transformative. Authors that heralded the developmental opportunities of telecentres gave examples of possibilities of overcoming extreme poverty or bureaucratic obstacles, of participating in public sector decisions and actions, and of overcoming corruption (Bailur, 2007). Some recent research that attempted to explain why telecentres very often prove unsustainable focused attention on fundamental questions of effective mechanisms for development, such as public/private partnership mechanism of governance for development (Madon, 2005). Kanungo's (2003) analysis of the sustainability of an initiative that uses IT to create 'knowledge centres' in Indian villages placed emphasis on the value of these centres in terms of a better informed and liberated society'. His Habermasian approach focused on the disruptive mechanisms enabled by IT that may form a basis for empowerment for the rural poor.

Nevertheless, a more careful reading of the ISDC literature on telecentres suggests that the endorsement of the general assumption of the developmental potential of the provision of ICT access to the communities does not necessarily make a transformative discourse. Indeed, only few authors associated telecentres and their sustainability with social change, such as the enactment of new forms of governance, or the breaking of deeply rooted social norms to allow the poor to have a say, as Madon (2005) and Kanungo (2003) do. Instead, much of the research assumed that telecentres are introduced in the existing socioeconomic structures and practices of disadvantaged communities and have a positive impact on lessening the gap between them and the advanced industrialized societies. In other words the discourse is of diffusion and adaptation of technologies and norms of modernity. 
A common expectation in the telecentres initiatives by many NGOs and governments, even in very poor communities, has been that, after investing some seed money, telecentres would form viable enterprises, able to cover the costs of their operations and to sustain a profitable business for local entrepreneurs (Harris et al., 2003). Consequently, research on telecentres has attempted to fit and adapt the economic rationality of profitable business, even though there is not much potential for profit making from telecentre 'customers' who live in extreme poverty and most of whom have little appreciation of the benefits they may gain from using ICT services (Madon et al., 2007).

As initial enthusiasm on the developmental expectations of telecentres has subsided, a lot can be learned from evaluation research (Reilly and Gomez, 2001). Socially embedded approaches offer a great deal of capacity to explain what matters in each case and what goes wrong, and perhaps to diagnose lurking problems or growth potential of ongoing initiatives, and to predict outcomes (Bailur, 2007).

\section{Theory building potential}

The distinctiveness of the ISDC research lies in its attention to the DCs' context of IS innovation and problematization of the developmental role of IS innovation. These research concerns are of course interrelated. Authors who study the socio-economic context of IS innovation often reflect on development issues. For example Korpela, whose main work concerns the adaptation of Western systems development practices for effective IS innovation in Nigeria, drew from his action research experience to reflect on the 'development status' of the country (Korpela, 1996b). Similarly, authors discussing the developmental role of IS innovation tend to refer to contextual characteristics that are implicated in the realization or frustration of particular ICT-mediated visions of 'development' (Akpan, 2003). Nevertheless, this analytical distinction suggests two areas where the ISDC research has the potential to make significant contributions: (a) on understanding how historically constructed social conditions (with cultural, economic, political and cognitive dimensions) are implicated in the IS innovation process and (b) on understanding how IS innovation is implicated in interventions for changing people's life conditions through different development ideologies and policies.

\section{Context in IS innovation}

General IS research has developed mainly universalistic and narrowly situated perspectives of innovation (Avgerou and Madon, 2004), paying relatively little attention to developing theory on the interplay between IS innovation and its socio-economic context. Universalistic perspectives follow general techno-economic reasoning to elaborate on the value of ICT and information and on the processes of IS innovation through which such value can be realized (Scott Morton, 1991; Hirschheim et al., 1996; Fulk and DeSanctis, 1999). They often acknowledge contextual contingencies, but assume an overriding rationality that determines universal goals of IS innovation and the logic of action towards their satisfaction (Porter and Millar, 1984; Ciborra and Andreu, 1998). Situated perspectives consider IS innovation as enacted by social actors and tend to place emphasis on meaning making and practice within the power dynamics of the immediate setting of the innovating organization (Suchman, 1994; Orlikowski et al., 1996). Suspicious of 'structuralist' theories of social change (Latour, 2004), they avoid accounts of long-lasting socioeconomic context of IS innovation.

ISDC research confronted the need to build analytical capability to account for IS innovation against a broader social context. ${ }^{10}$ To that end, it found theoretical grounding in contemporary social theory, such as Actor Network Theory, structuration theory, organizational institutionalism. These provided insights and vocabularies to address conceptual relationships such as technology/society, agency/structure, technical reasoning/institutional dynamics, while the main objective of contextualist ISDC studies has been the development of theoretical capacity for addressing questions concerning the way specific categories of technologies and social actors clusters are formed, shape each other, and construct particular socio-economic effects (Gregor, 2006).

Early efforts to account for IS innovation in relation to its context built on Pettigrew's contextualist theory, which views particular instances of organizational interventions as processes unfolding through time in relation to layers of context: typically, the organizational setting and its national environment (Pettigrew, 1985; Walsham, 1993). Madon, for example, followed Pettigrew's contextualist analysis to study the introduction of computers for the management of a rural development programme in India's local administration districts. Her analysis encompassed work norms within the district bureaucracies as well as cultural aspects of the Indian rural setting within which the rural development initiative and its administration were embedded (Madon, 1993). While Pettigrew's contextualist approach continues to be followed in ISDC studies (Braa et al., 2007a), several other theoretical approaches have been introduced to explore IS innovation in the developing countries' context, including neo-institutionalist and social constructionist analyses (Avgerou, 2001; Avgerou, 2003a; Miscione, 2007; Silva, 2007).

Culture has received particular attention in contextualist ISDC research, engaging all three ISDC discourses. The adaptive discourse frames the relationship of IS and culture in terms of a transfer of ICT applications into a nonWestern national culture, which is usually seen as posing obstacles to innovation and as being a source of resistance (Struab et al., 2001). Hofstede's model of national culture variables and cultural difference (Hofstede, 1984) is often used to analyse conflicts between values embedded into and behaviours required by ICT and the national culture of developing countries (Leidner and Kayworth, 2006). Nevertheless, such studies have been repeatedly criticized by IS scholars as oversimplifying cultural difference, see for example Myers and Tan (2002); they 'sweep the subtleties of cultural difference under the universal carpet' as Walsham put it in his extensive discussion of examples of ISDC studies of IS innovation and culture (Walsham, 2001).

Research within the socially embedded and transformative discourses has produced more nuanced insights of culture and IS innovation. Focusing on the embeddedness of innovation in a national culture has led many authors to 
highlight features of historically formed collective behaviour that require attention when designing appropriate ICT systems, or when organizing the innovation process, such as attitude to hierarchy, arranging action in time, sense of space and geography (Sahay, 1998; Rohitratana, 2000; Zakaria et al., 2003). Attention has been drawn to cross-cultural interactions. Such studies overcome the juxtaposition of IS innovation - assumed to be inscribed with Western culture - with DC culture - assumed to be bent to accommodate it (Walsham, 2002).

Particularly promising is the research that suggests a concept of culture which is dynamic and emergent, 'constantly being maintained and changing', and seen as an ongoing accomplishment (Westrup et al., 2003). Such research transcends the ICT/culture fit or conflict. Neither ICT nor culture are taken to be uni-dimensional determinants of values and behaviours. ICT, seen as a hybrid network of artefacts, people, and institutions, is subject to negotiation and local IS innovation shaping. Cultural influence on IS innovation, seen as a historically formed disposition for a particular behaviour, may stem from the innovating organization, its national or regional environment, or the social class of individual actors. And rather than IS innovation fitting in or conflicting with the culture of its social context, of particular interest is the mutual reconstitution of IS innovation and the cultures that influence it. Moreover, cultural influence needs to be considered along with political and economic rationalities implicated in actor behaviour. Such a dynamic approach to studying IS innovation and culture, although still in its infancy in ISDC studies, opens new scope for developing more relevant contextualist accounts than the currently prevailing studies that assess progress of innovation against assumed desirable values and behaviours.

\section{ICT and development}

Many ISDC studies have been premised on the potential developmental role and effects of IS diffusion derived from theoretical perceptions of desirable world orders, such as Sen's theory of capabilities (Madon, 2004) or conceptual models of assumed transformations happening in the contemporary world that necessitate ICT infrastructures, such as Castells' ideas of society and economy as networks (Braa et al., 2004).

But development is a controversial notion, subject to a long theoretical debate, and development policy and action are entangled with the conflicting interests and power relations that comprise the contemporary global and national politics. Indeed, the international agencies' policies for economic growth and institutional changes are widely and strongly contested in developing countries. Within ISDC, some authors drew from Escobar's Foucauldian critiques of the discourse on development and voiced suspicion about the development policies IS innovation interventions are intended to support (Thompson, 2004). Some literature has taken a critical stance to the currently prevailing development ideas that drive the discourse on digital divide and justifies IS innovation in terms of creating a country's competitiveness capabilities in a global free market, and some authors pointed out the ongoing controversies about the validity of this theoretical position and suspicions on the motives of the agencies that promote them (Heeks and Kenny, 2002; Avgerou, 2003b; Ciborra, 2005; Westrup and Al-Jaghoub, forthcoming).

Thus, while ISDC research rests on the assumption that ICTs are relevant to the developing countries (Sahay, 2001; Walsham et al., 2007), an important aspect of this research area is the recognition that the course of IS innovation and its effects for DC societies are closely associated with the socio-economic policies within which they take place. ISDC studies can be a valuable source of evidence for the validity of techno-economic development theories that guide ICT and socio-economic reform policy. The empirical observation and theoretical analyses of IS innovation processes may fill the knowledge gap between the general economic propositions about ICT and economic growth and the particular courses of action that attempt to achieve socioeconomic improvements through introducing ICT and organizational change. Let us look, for example, at the way ISDC research complements the economic arguments about the developmental role of the internet. A currently prevalent argument about the economic significance of the internet is based on the view of telecommunications as a mechanism for the communication of market prices and therefore for efficient market outcomes. It is thus predicted that the diffusion of telecommunications technology, such as the internet, will help farmers to decide what is best to produce, when and where from to buy seeds and fertilizers, and where to sell their products to get the best price (Eggleston et al., 2002). It is also expected to reduce excessive reliance on exploitative middlemen. Evidence for such a scenario of economic benefits for the rural poor is limited. Economists tend to draw support for the cause and effect relationship between diffusion of telecommunications and economic growth from historical studies on now advanced industrial economies. Searching for evidence in the contemporary setting of developing countries, Eggleston et al. highlight the example of the Grameen Bank Pay Phone initiative in Bangladesh (Bhatnagar, 2003). They also present findings of correlation of telephone diffusion and improved economic indicators in Chinese villages - though the authors are aware that such a correlation may suggest a reverse causality, that is, the diffusion of telephones following economic growth that resulted from other factors.

However, other economic and non-economic mechanisms may negate the creation of the predicted benefits. The relationship of ICT and economic growth implicates processes of change of social and individual behaviour that are poorly understood. And this is where ISDC research provides valuable findings for developing theory. For example, research that examined the sustainability failure of telecentres that were intended to provide market information sources to rural villages showed the concerns that drive people's participation or distance from such innovation, despite its developmental promise (Harris et al., 2003; Bailur, 2007). Similarly, socially embedded analyses of business IS innovation cases show some of the reasons why the 'productivity paradox' of continuing ICT diffusion without the expected productivity increases continues in developing countries (Mann, 2004).

In short, ISDC has a lot to contribute by engaging with the ongoing research and debate in studies of the international political economy and in institutional 
economics. To that end, empirical ISDC research needs to associate the study of IS innovation with the particular socio-economic rationale and policies of development that provide its underlying justification and targets.

\section{Conclusions}

A panel at the International Conference on Information Systems (ICIS) in 1997 discussed the question 'why should IS academics and professionals devote attention to developing countries?' The answer the panellists mostly elaborated on was that developing countries are a huge and yet untapped market. In contrast, Walsham has repeatedly pointed out the ethical significance of researching the way ICT may come to bear on improving the life conditions of the vast majority of people who are born in non-affluent regions of the contemporary world (Walsham, 2001). These views demonstrate the varying motives of researchers from Western countries. But, with an increasing number of IS researchers from developing countries and an increasing number of IS professionals working on global IS infrastructures that include DCs, ISDC research is in less need of justification as a field of enquiry concerned with the way ICT may benefit 'others'. The value of this research area can be judged in terms of its contribution to understanding IS innovation and its socio-economic consequences across an increasingly interlinked world. To that end, I conclude this outline of ISDC research with some comments on the knowledge it has added, or can potentially add to the IS field. First I summarize the contributions made through the diffusion and social embeddedness discourses, and highlight their potential for developing further analytical capacity to understand IS innovation in the contemporary development context. Then I discuss the potential of the transformative discourse, which, although the least developed in comparison to the diffusion and social embeddedness, I believe is the most novel and challenging for the IS field.

Both the diffusion and the socially embedded discourses are well established in the general IS research. The ISDC studies have enriched them substantially. At the very least they have increased awareness that in different countries and regions the circumstances of IS innovation are different. This is demonstrated by the particular issues and new themes that came to comprise the ISDC research agenda. In different parts of the contemporary world IS innovation is found to be associated with different hopes and expectations, concerns and fears, observed behaviours and reflections. And both the diffusion/adaptation and the social embeddedness discourses share the assumption that these differences matter, they do not disappear by the force of technology or managerial logic alone. But their approach to understanding and acting upon the differences of the IS innovation context differs.

The diffusion discourse does so by further assuming that the material/cognitive entities that comprise ICT and associated best practices of organizing are adequately independent from the social circumstances that give rise to them to be transferable, more or less intact, into any other society. Consequently, subject to suitable adaptation, these entities can make a desirable impact. Such research, therefore, traces the particular factors that capture the differences of the recipient country and organization that are likely to affect the innovation process - such as economic conditions, technology competences, people's attitudes to IT, institutionalized work place habits. Consequently, it designs modifications of the technologies and interventions in the recipient institutions to make them hospitable to the intended innovation.

The social embedded innovation discourse finds this assumption about the nature of IS oversimplifying and misleading. It has developed more elaborate ontologies of IS innovation as socially constructed entities, and therefore contingent in their perceived significance and their interplay with human actors and their social institutions. The focal point of the research is the process of innovation in situ, thus tracing the cognitive, emotional, and political capacities that individuals nurtured in their local social institutions bring to bear on unfolding innovation attempts. Through this approach the socially embedded innovation discourse sheds light on what, regarding an attempted innovation, is locally meaningful, desirable, or controversial, and therefore how innovation emerges (or is retarded) from the local social dynamics. With attention to local concerns, situated meanings of ICT, and courses of reasonable action that often differ from the taken-forgranted rationality of IS innovation, ISDC studies reveal a much more complex picture of the IS innovation effort than the general IS field has constructed, see for example Miscione (2007).

A more challenging task following the recognition of the significance of contextual contingency, that both the diffusion and the social embeddedness discourses share, is to identify the context that matters and develop theory capable of addressing the interrelationship of context with IS innovation. To my judgement the social embeddedness discourse is in a better position to do so. As it has been developed in close association with contemporary social theory, its elaborate socio-technical concepts address more effectively the dynamic interplay between the artefacts/ cognitive constructs of IS innovation and the multiple and changing social dimensions in developing countries.

The third discourse, the transformative IS innovation intervention, introduces new elements in the IS research field. First, it expands the domain of IS research beyond the organization or inter-organizational links and addresses questions related with institutions of broader social collectivities. This is discernible in the literature that examines the developmental potential of ICT and the way such potential can be exploited. For example the transformative discourse on telecentres is cast primarily in terms of the developmental needs of a society and seeks relevant insights from macro-societal theories. Some macro-theoretical perspectives are already present in the IS field, for example in identifying the economic trends within which business innovate for competitiveness. But, as I argued in this paper, ISDC research introduces in the IS field the interdisciplinary macro-theoretical complexity concerning questions on IS innovation and 'development'.

Second, the transformative interventions discourse has a kind of criticality that is unprecedented in the IS field. The literature that discusses the developmental potential of ICT and associates IS innovation initiatives with social, political, and economic change articulates critical views about the 
power relations within specific developing countries and the world at large. The IS field, though familiar with critical discourses, mainly regarding the organizational level politics of the work place (Howcroft and Trauth, 2005), has rarely engaged in macro-political analyses regarding ICT and institutional change. A noticeable exception is the critique of the government policy proposals for identity cards in the UK by IS scholars (Whitley et al., 2007). But the ISDC studies that concern the role of ICT in the struggle for the transformation of the life conditions of the billions of poor - with implications for the lives of the affluent inevitably come to refer to political ideologies of development (such as the 'Washington consensus' or 'basic needs' views), and to policies and actions of development institutions (such as the World Bank, the aid agencies of 'Western' countries, international NGOs). Analyses of the IS innovation context include controversial government policies, such as liberalization of telecommunications for extending connectivity, or the filtering of internet information by national governments.

In short, in this paper I argued that ISDC research has expanded the IS research agenda and developed new understanding of IS innovation phenomena, mainly through its attention to social context and strategic concerns associated with socio-economic development. As it encounters questions on policy and practice of development, it is confronted with critical issues associated with the role of ICTs in the transformation of social relations and macro-level institutions. I hope that the IS research community will recognize the significance of this enlargement of its domain of inquiry, encourage and foster it.

\section{Notes}

1 See, The Information Society, Vol. 19, No. 1, 2003; Information Technology and People, Vol. 16, No. 1, 2003; MISQ, Vol. 31, No. 2, 2006.

2 A landmark in the emergence of the ISDC research was the first IFIP conference in New Dehli, in 1988, see Bhatnagar and BjørnAndersen (1990).

3 This is a point of difference of IS research and studies concerning ICTs in other fields such as economics as well as the studies concerning ICT published by international development organizations, such as the World Bank. A great deal of the research by the latter is concerned with scarcity of technology and skills and is directed towards creating awareness about the significance of ICTs and motivating the allocation of relevant resources and effort for overcoming it. Although ISDC research often aims at creating awareness of the developmental potential of ICT, it is mainly pre-occupied with the experience of ICT innovation in developing countries and the socioorganizational processes involved.

4 I am grateful to Wanda Orlikowski for bringing the similarity of the ISDC discourses I identify in this article with Deetz's discourse categories.

5 The 'consensus' orientation is adopted, for example, in research which considers IS innovation an enabler for accommodating developing countries in the world socio-economic order, or in research concerned with the fit of IS innovation in local cultures.

6 See for example the expectations captured in the term 'leapfrogging' Davison et al. (2000).
7 Seventh IFIP WG9.4 conference on 'Information \& Communication Technologies and Development: New Opportunities, Perspectives \& Challenges', Indian Institute of Management, Bangalore, May 29-31, 2002.

8 See, for example, the sites of the World Summit for the Information Society (WSIS) initiative of the United Nations and the International Telecommunications Union http://www. itu.int/wsis/index.html.

9 For information about IDRC's telecentre initiative, see http:www.idrc.ca/acacia/index.html. Other initiatives for the creation of community telecentres by international development organizations include ITU's (http:www.itu.int/ITU-D/index. html); UNESCO's (http:www.unesco.org/websowlr/iip/\#funding) and the World Bank's (http:worldbank.org/html/fpd/telecoms/ subtelecom/selected_projects.htm).

10 Not all ISDC research overcomes the limitations of universalistic or narrowly situated approaches. Most of the studies within the diffusion and adaptation category of discourse and some studies in the transformative category assume universal imperatives for ICT innovation and socio-economic targets. Many of the studies in the socially embedded category are narrowly situated, uncovering meanings and behaviours of the actors involved in IS innovation without, however, explaining the social conditions which have formed and sustained them, and which are therefore challenged by the innovation intervention.

\section{References}

Adelakum, O. (2005). Offshore IT Outsourcing To Emerging Economies Analysis of Readiness vs Attractiveness, in A. O. Bada and A. Okunoye. (eds.) Proceedings of the Eighth International Working Conference of IFIP WG9.4: Enhancing human resource development through ICT (Abuja-Nigeria, 2005).

Akpan, P.I. (2003). Basic-Needs to Globalization: Are ICTs the missing link? Information Technology for Development 10: 261-274.

Akrich, M. (1992). The De-scription of Technical Objects, in W.E. Bijker and J. Law (eds.) Shaping Technology/Building Society, Cambridge: MIT Press, pp. 205-224.

Al-Gahtani, S.S. (2003). Computer Technology Adoption in Saudi Arabia: Correlates of perceived innovation attributes, Information Technology for Development 10(1): 57-69.

Al-Jaghoub, S. and Westrup, C. (2003). Jordan and ICT-led Development: Towards a competition state? Information Technology \& People 16(1): 93-110.

Avgerou, C. (1990). Computer Based Information Systems and Modernization of Public Administration in Developing Countries, in S. Bhatnagar and N. Bjørn-Andersen (eds.) Information Technology in Developing Countries, Amsterdam: North-Holland, pp. 243-250.

Avgerou, C. (1996). Transferability of Information Technology and Organisational Practices, in M. Odedra-Straub (ed.) Global Information Technology and Socio-Economic Development, Nashua, NH: Ivy League, pp. 106-115.

Avgerou, C. (2001). The Significance of Context in Information Systems and Organisational Change, Information Systems Journal 11: 43-63.

Avgerou, C. (2002). Information Systems and Global Diversity, Oxford: Oxford University Press.

Avgerou, C. (2003a). IT as an Institutional Actor in Developing Countries, in S Krishna and S. Madon (eds.) The Digital Challenge: Information technology in the development context, Aldershot: Ashgate, pp. 46-62.

Avgerou, C. (2003b). The Link Between ICT and Economic Growth in the Discourse of Development, in M. Korpela, R. Montealegro and A. Poulymenakou (eds.) Organizational Information Systems in the Context of Globalization, Dordrecht: Kluwer, pp. 373-386.

Avgerou, C. and Land, F. (1992). Examining the Appropriateness of Information Technology, in S. Bhatnagar and M. Odedra (eds.) Social 
Implications of Computers in Developing Countries, New Delhi: Tata McGraw-Hill, pp. 26-42.

Avgerou, C. and Madon, S. (2004). Framing IS Studies: Understanding the social context of IS innovation, in C. Avgerou, C. Ciborra and F. Land (eds.) The Social Study of Information and Communication Technology: Innovation, actors, and contexts, Oxford: Oxford University Press, pp. 162-182.

Avgerou, C. and Walsham, G. (eds.) (2000). Information Technology in Context: Studies from the perspective of developing countries, London: Ashgate.

Bada, A.O. (2002). Local Adaptations to Global Trends: A study of an IT-based organizational change programme in a Nigerian bank, The Information Society 18(2): 77-86.

Barrett, M. and Walsham, G. (1995). Managing IT for Business Innovation: Issues of culture, learning, and leadership in a Jamaican insurance company, Journal of Global Information Management 3(3): 25-33.

Bailur, S. (2007). Using Stakeholder Theory to Analyze Telecenter Projects, Information Technologies and International Development 3(3): 61-80.

Bell, S. and Wood-Harper, A.T. (1990). Information Systems Development for Developing Countries, in S.C. Bhatnagar and N. Bjørn-Andersen (eds.) Information Technology in Developing Countries, Amsterdam: NorthHolland, pp. 23-40.

Bhatnagar, S.C. (2003). Development and Telecommunications Access: Cases from South Asia, in C. Avgerou and R.L. La Rovere (eds.) Information Systems and the Economics of Innovation, Cheltenham: Edward Elgar, pp. 33-52.

Bhatnagar, S.C. and Bjørn-Andersen, N. (eds.) (1990). Information Technology in Developing Countries, Amsterdam: North-Holland.

Bhatnagar, S.C. and Odedra, M. (eds.) (1992). Social Implications of Computers in Developing Countries, New Delhi: Tata McGraw-Hill.

Braa, J., Hanseth, O., Heywood, A., Mohammed, W. and Shaw, V. (2007a). Developing Health Information Systems in Developing Countries: The flexible standards strategy, MIS Quarterly 31(2): 381-402.

Braa, J., Monteiro, E. and Sahay, S. (2004). Networks of Action: Sustainable health information systems across developing countries, MIS Quarterly 28(3): 337-362.

Braa, J., Monteiro, E., Sahay, S., Staring, K. and O.H., T. (2007b). Scaling up Local Learning - Experiences from South-South-North Networks of Shared Software Development, IFIP WG9.4 9th International Conference 'Taking Stock of E-Development' (Sao Paulo, 2007b). Available at http://www.ifip94.org.br/ifip94fullpapers.htm.

Brynjolfsson, E. and Hitt, L. (1993). Is Information Systems Spending Productive? New Evidence and New Results, in J.I. DeGross, R.P. Bostrom and D. Robey (eds.) Proceedings of the Fourteenth International Conference on Information Systems (Orlando, Florida, 1993); pp. 47-64.

Byrne, E. and Jolliffe, B. (2007). Free and Open Source Software: Development as freedom?, IFIP WG9.4 9th International Conference 'Taking Stock of E-Development' (Sao Paulo, 2007). Available at http://www.ifip94.org.br/ ifip94fullpapers.htm.

Carmel, E. (2003a). The Globalization of Software Outsourcing to Dozens of Nations: A preliminary analysis of the emergence of 3rd and 4th tier software exporting nations, in S. Krishna and S. Madon (eds.) The Digital Challenge: Information technology in the development context, Aldershot: Ashgate, pp. 359-367.

Carmel, E. (2003b). The New Software Exporting Nations: Impacts on national well being resulting from their software exporting industries, Electronic Journal on Information Systems in Developing Countries 13(3): 1-6.

Carmel, E. (2003c). Taxonomy of New Software Exporting Nations, Electronic Journal on Information Systems in Developing Countries 13(2): 1-6.

Carmel, E. and Agarwal, R. (2002). The Maturation of Offshore Sourcing of Information Technology Work, MIS Quarterly Executive 1(2): 65-77.

Cecchini, S. and Scott, C. (2003). Can Information and Communications Technology Applications Contribute to Poverty Reduction? Lessons from Rural India, Information Technology for Development 10: 73-74.

Ciborra, C. (2005). Interpreting E-government and Development: Efficiency, transparency or governance at a distance? Information Technology \& People 18(3): 260-279.

Ciborra, C. and Andreu, R. (1998). Organizational Learning and Core Capabilities Development: The role of IT, in R.D. Galliers and W.R.J. Baets (eds.) Information Technology and Organizational Transformation, Chichester: John Wiley, pp. 87-106.

Ciborra, C.U. and Associates (eds.) (2000). From Control to Drift, Oxford: Oxford University Press.
Commander, S. (2005). The Software Industry in Emerging Markets, Cheltenham: Edward Elgar.

Davis, C., McMaster, J. and Nowak, J. (2002). IT-enabled Services as Development Drivers in Low-income Countries: The case of Fiji, Electronic Journal on Information Systems in Developing Countries 9: 1-18.

Davis, F.D. (1989). Perceived Usefulness, Perceived Ease of Use, and User Acceptance of Information Technology, MIS Quarterly 13(3): 319-340.

Davison, R., Vogel, D.R., Harris, R. and Jones, N. (2000). Technology Leapfrogging in Developing Countries - An Inevitable Luxury? Electronic Journal on Information Systems in Developing Countries 1(5): 1-10.

Deetz, S. (1996). Describing Differences in Approaches to Organization Science: Rethinking Burrell and Morgan and their legacy, Organization Science 7(2): 191-207.

Eggleston, K., Jensen, R. and Zeckhauser, R. (2002). Information and Communication Technologies, Markets and Economic Development, in G.S. Kirkman, P.K. Cornelius, J.D. Sachs and K. Schwab (eds.) The Global Information Technology Report: readiness for the networked world, New York: Oxford University Press, pp. 62-75.

Fulk, J. and DeSanctis, G. (1999). Articulation of Communication Technology and Organizational Form, in G. DeSanctis and J. Fulk (eds.) Shaping Organization Form: Communication, connection, and community, Thousand Oaks, CA: Sage, pp. 5-32.

Goonatilake, L., Maizza-Neto, O. and Jayawardene, P. (2000). Enhancing Enterprise Competitiveness in Developing Countries Through the Promotion of Management Information and Benchmarking Tools, in S. Sahay, J. Miller and D. Roode (eds.) Proceedings of the Sixth International Working Conference of IFIP WG 9.4: Information flows, local improvisations and work practices. STS Conferences(Cape Town, 2000).

Gregor, S. (2006). The Nature of Theory in Information Systems, MIS Quarterly 30(3): 611-642.

Harris, R.W., Kumar, A. and Balaji, V. (2003). Sustainable Telecentres? Two Cases from India, in S. Krishna and S. Madon (eds.) The Digital Challenge: Information technology in the development context, Aldershot: Ashgate, pp. 124-135.

He, X. (2004). The ERP Challenge in China: A resource-based perspective, Information Systems Journal 14: 153-167.

Heeks, R. (1990). Fourth Generation Languages (4GLs) and the Indian Software Industry, in S.C. Bhatnagar and N. Bjørn-Andersen (eds.) Information Technology in Developing Countries, Amsterdam: North-Holland, pp. 251-264.

Heeks, R. (2002). Information Systems and Developing Countries: Failure, success and local improvisations, The Information Society 18(2): 101-112.

Heeks, R. and Bailur, S. (2007). Analyzing E-government Research: Perspectives, philosophies, theories, methods, and practice, Government Information Quarterly 24(2): 243-265.

Heeks, R. and Kenny, C. (2002). ICTs and Development: Convergence or divergence for developing countries? Information and Communication Technologies and Development: New Opportunities, Perspectives and Challenges, IFIP WG9.4 Conference: Bangalore.

Hirschheim, R., Klein, H.K. and Lyytinen, K. (1996). Exploring the Intellectual Structures of Information Systems Development: A social action theoretic analysis, Accounting, Management and Information Technologies 6(1/2): $1-63$.

Hitt, L. and Brynjolfsson, E. (1996). Productivity, Business Profitability and Consumer Surplus: Three different measures of information technology value, MIS Quarterly 20(2): 121-142.

Hofstede, G. (1984). Culture's Consequences: International Differences in Work Related Values, London: Sage.

Howcroft, D. and Trauth, E.M. (eds.) (2005). Handbook of Critical Information Systems Research, Cheltenham: Edward Elgar.

Hunt, P. (2001). True Stories: Telecentres in Latin America and the Caribbean, EJISDC 4(5): 1-17.

Jarvenpaa, S.L. and Leidner, D.E. (1998). An Information Company in Mexico: Extending the resource-based view of the firm to a developing country context, Information Systems Research 9(4): 342-361.

Kanungo, S. (2003). Information Village: Bridging the digital divide in rural India, in S. Krishna and S. Madon (eds.) The Digital Challenge: Information Technology in the Development Context, Aldershot: Ashgate, pp. 104-123.

Kenny, C.J. (2000). Expanding Internet Access to the Rural Poor in Africa, Information Technology for Development 9(1): 25-32. 
Kiely, G. and Fitzgerald, B. (2005). An Investigation of the Use of Methods Within Information Systems Development Projects, Electronic Journal on Information Systems in Developing Countries 22(4): 1-13.

Kirkman, G.S., Cornelius, P.K., Sachs, J.D. and Schwab, K. (2002). The Global Information Technology Report 2001-2002: Readiness for the networked world, New York: Oxford University Press.

Korpela, M. (1996a). Computer systems Development for "Delinking" in Nigeria, in M. Odedra-Straub (ed.) Global Information Technology and Socio-Economic Development, Nashua, NH: Ivy League, pp. 116-129.

Korpela, M. (1996b). Traditional Culture or Political Economy? On The Root Causes of Organizational Obstacles of IT in Developing Countries, Information Technology for Development 7(1): 29-42.

Korpela, M., Soriyan, H.A., Olufokunbi, K.C. and Mursu, A. (2000). Madein-Nigeria Systems Development Methodologies: An action research project in the Health sector, in C. Avgerou and G. Walsham (eds.) Information Technology in Context: Studies from the perspective of developing countries, Aldershot: Ashgate, pp. 113-133.

Kraemer, K.L., Dedrick, J., Melville, N.P. and Zhu, K. (eds.) (2006). Global e-Commerce, Cambridge: Cambridge University Press.

Krishna, S. and Madon, S. (2002). Information \& Communication Technologies and Development: New opportunities, perspectives \& challenges, Seventh International Working Conference of IFIP WG 9.4, Indian Institute of Management Bangalore (Bangalore, 2002).

Krishna, S. and Madon, S. (eds.) (2003). The Digital Challenge: Information Technology in the Development Context, Aldershot: Ashgate.

La Rovere, R. (1996). Diffusion of IT and the Competitiveness of Brazilian Banking, in E.M. Roche and M.J. Blaine (eds.) Information Technology, Development and Policy, Aldershot: Avebury, pp. 95-112.

La Rovere, R.L. and Pereira, M.V.R. (2000). Adoption of ICT and Competitiveness in the Tourism Sector: The case of Brazilian travel agencies, in S. Sahay, J. Miller and D. Roode (eds.) Proceedings of the Sixth International Working Conference of IFIP WG 9.4: Information flows, local improvisations and work practices, SBS Conferences (Cape Town, 2000).

Lacity, M. and Hirschheim, R. (1993). Information Systems Outsourcing, Chichester: Wiley.

Lacity, M.C. and Willcocks, L.P. (1998). An Empirical Investigation of Information Technology Sourcing Practices: Lessons from experience, MIS Quarterly 22(3): 363-408.

Latour, B. (2004). On Using ANT for Studying Information Systems: A (somewhat) Socratic dialogue, in C. Avgerou, C. Ciborra and F. Land (eds.) The Social Study of Information and Communication Technology, Oxford: Oxford University Press, pp. 62-76.

Leidner, D.E. and Kayworth, T. (2006). A review of Culture in Information Systems Research: Toward a theory of information technology culture, MIS Quarterly 30(2): 357-399.

Lind, P. (2000). On the Design of Management Assistance Systems for SMEs in Developing Countries, in C. Avgerou and G. Walsham (eds.) Information Technology in Context: Studies from the perspective of developing countries, Aldershot: Ashgate, pp. 40-55.

Lind, P., Sepulveda, E. and Nunez, J. (2000). On the Applicability of a Computer Model for Business Performance Analysis in SMEs: A case study from Chile, Information Technology for Development 9(1): 33-44.

Lyytinen, K. and Hirschheim, R. (1987). Information Systems Failures: A survey and classification of the empirical literature, Oxford Surveys in Information Technology 4: 257-309.

Madon, S. (1992). Computer Based Information Systems for Development Planning, in S.C. Bhatnagar and M. Odedra (eds.) Social Implications of Computers in Developing Countries, New Delhi: Tata McGraw-Hill, pp. 209-217.

Madon, S. (1993). Introducing Administrative Reform Through the Application of Computer-based Information Systems: A case study in India, Public Administration and Development 13: 37-48.

Madon, S. (2004). Evaluating the Developmental Impact of E-governance Initiatives: An exploratory framework, Electronic Journal on Information Systems in Developing Countries 20(5): 1-13.

Madon, S. (2005). Governance Lessons from the Experience of Telecentres in Kerala, European Journal of Information Systems 14(4): 401-416.

Madon, S., Reinhard, N., Roode, D. and Walsham, G. (2007). Digital Inclusion Projects in Developing Countries: Processes of institutionalisation, IFIP WG9.4 9th International Conference 'Taking Stock of E-Development' (Sao Paulo, 2007). Available at http://www.ifip94.org.br/ifip94fullpapers.htm.
Madon, S. and Sahay, S. (1996). Geographic Information Systems for Development Planning in India: Challenges and opportunities, in M. OdedraStraub (ed.) Global Information Technology and Socio-Economic Development, Nashua, NH: Ivy League, pp. 42-52.

Mann, C.L. (2004). Information Technologies and International Development: Conceptual clarity in the search for commonality and diversity, Information Technologies and International Development 1(2): 67-79.

Mbarika, V.W., Kah, M.M.O., Musa, P.H., Meso, P. and Warren, J. (2003). Predictors of Growth of Teledensity in Developing Countries: A focus on middle and low-income countries, Electronic Journal on Information Systems in Developing Countries 12(1): 1-16.

Mbarika, V.W., Payton, F.C., Kvasny, L. and Amadi, A. (2007). IT Education and Workforce Participation: A new era for women in Kenya? The Information Society 23(1): 1-18.

Miscione, G. (2007). Telemedicine in the Upper Amazon: Interplay with local health care practices, MIS Quarterly 31(2): 403-425.

Molla, A. (2000). Downloading or Uploading? The Information Economy and Africa's Current Status, Information Technology for Development 9: 205-221.

Monteiro, E. (1998). Scaling Information Infrastructure: The case of next generation IP in internet, The Information Society 14: 229-245.

Munkvold, B.E. and Tundui, H.P. (2005). The Role of IT in Supporting Women Entrepreneurs in Urban Tanzania, in A.O. Bada and A. Okunoye (eds.) Proceedings of the Eighth International Working Conference of IFIP WG9.4: Enhancing human resource development through ICT (Abuja-Nigeria, 2005).

Mursu, A., Soriyan, H.A. and Korpela, M. (2003). Risky Business: A case study on information systems development in Nigeria, in S. Krishna and S. Madon (eds.) The Digital Challenge: Information Technology in the Development Context, Aldershot: Ashgate, pp. 318-339.

Myers, M.D. and Tan, F.B. (2002). Beyond Models of National Culture in Information Systems Research, Journal of Global Information Management 10(1): 24-32

Ngwenyama, O., Andoh-Baidoo, F.K., Bollou, F. and Morawczynski, O. (2006) Is there a Relationship Between ICT, Health, Education and Development? An Empirical Analysis of Five West African Countries from 1997-2003, Electronic Journal on Information Systems in Developing Countries 23(5): $1-11$.

Nicholson, B. and Sahay, S. (2001). Some Political and Cultural Issues in the Globalisation of Software Development: Case experience from Britain and India, Information and Organization 11: 25-43.

Nicholson, B. and Sahay, S. (2004). Embedded Knowledge and Offshore Software Development, Information and Organization 14: 329-365.

Nicholson, B. and Sahay, S. (2007). Software Exports Development in Costa Rica: Contradictions and the potential for change, IFIP WG9.4 Ninth International Conference 'Taking Stock of E-Development' (Sao Paulo, 2007). Available at http://www.ifip94.org.br/ifip94fullpapers.htm.

Odedra-Straub, M. (1993). Critical Factors Affecting Success of CBIS: Cases from Africa, Journal of Global Information Management 1(3): 16.

Odedra-Straub, M. (ed.) (1996). Global Information Technology and Socio-economic Development, Nashua, NH: Ivy League.

Orlikowski, W.J. (1996). Improvising Organizational Transformation over Time: A situated change perspective, Information Systems Research 7(1): 63-92.

Orlikowski, W.J., Walsham, G., Jones, M.R. and DeGross, J.I. (eds.) (1996). Information Technology and Changes in Organizational Work, London: Chapman \& Hall.

Pettigrew, A.M. (1985). Contextualist Research and the Study of Organisational Change Processes, in E. Mumford, R. Hirschheim, G. Fitzgerald and A.T. Wood-Harper (eds.) Research Methods in Information Systems, Amsterdam: North-Holland, pp. 53-78.

Porter, M. and Millar, V. (1984). How Information Gives You Competitive Advantage, Harvard Business Review 63(4): 149-160.

Reilly, K. and Gomez, R. (2001). Comparing Approaches: Telecentre evaluation experiences in Asia and Latin America, EJISDC 4(3): 1-17.

Roche, E.M. and Blaine, M.J. (eds.) (1996). Information Technology, Development and Policy, Aldershot: Avebury.

Roets, R.A., Minnaar, M.L. and Wright, K. (2007). Open Source: Towards successful systems development projects in developing countries, IFIP WG9.4 Ninth International Conference 'Taking Stock of E-Development' (Sao Paulo, 2007). Available at http://www.ifip94.org.br/ifip94fullpapers.htm.

Rogers, E.M. (1995). Diffusion of Innovations, New York: The Free Press. 
Rohitratana, K. (2000). The Role of Thai Values in Managing Information Systems: A case study of implementing an MRP system, in C. Avgerou and G. Walsham (eds.) Information Technology in Context: Implementing systems in the developing world, Aldershot: Ashgate, pp. 23-39.

Rose, G. and Straub, D. (1998). Predicting General IT Use: Applying TAM to the Arabic world, Journal of Global Information Management 6: 39-46.

Sahay, S. (1998). Implementing GIS Technology in India: Some issues of time and space, Accounting, Management and Information Technologies 8: $147-188$.

Sahay, S. (2001). Introduction to the Special Issue on "IT and Health Care in Developing Countries", Electronic Journal on Information Systems in Developing Countries 5(0): 1-6.

Sahay, S. and Avgerou, C. (2002). Special Issue on IS in Developing Countries, The Information Society.

Sahay, S., Nicholson, B. and Krishna, S. (2003). Global IT Outsourcing: Software development across borders, Cambridge: Cambridge University Press.

Sahay, S. and Walsham, G. (1995). Information Technology in Developing Countries: A need for theory building, Information Technology for Development 6(3/4): 111-124.

Sahay, S. and Walsham, G. (2006). Scaling of Health Information Systems in India: Challenges and approaches, Information Technology for Development 12(3): 185-200.

Sauer, C. (1999). Deciding the Future for IS Failures: Not the choice you might think, in B. Galliers and W.L. Currie (eds.) Rethinking Management Information Systems, Oxford: Oxford University Press, pp. 279-309.

Scott Morton, M.S. (1991). The Corporation of the 1990s: Information technology and organizational transformation, New York: Oxford University Press.

Silva, L. (2002). Outsourcing as an Improvisation: A case study in Latin America, The Information Society 18(2): 129-138.

Silva, L. (2007). Institutionalization does not Occur by Decree: Institutional obstacles in implementing a land administration system in a developing country, Information Technology for Development 13(1): 27-48.

Star, S.L. and Ruhleder, K. (1996). Steps Toward an Ecology of Infrastructure: Design and access for large information spaces, Information Systems Research 7: 111-133.

Strassmann, P. (1985). Information Payoff: The Transformation of Work in the Electronic Age, New York: Free Press.

Struab, D., Loch, K.D. and Hill, C.E. (2001). Transfer of Information Technology to the Arab World: A test of cultural influence modeling, Journal of Global Information Management 9(4): 6-48.

Suchman, L. (1994). Working Relations of Technology Production and Use, Computer Supported Cooperative Work 2: 21-39.

Thompson, M.P.A. (2004). ICT, Power, and Developmental Discourse: A critical analysis, Electronic Journal on Information Systems in Developing Countries 20(4): 1-26.

Tigre, P.B. (2003). Brazil in the Age of Electronic Commerce, The Information Society 19(1): 33-43.

UNDP (2001). Human Development Report 2001, New York: Oxford University Press.

United Nations Development Programme (2001). Making new technologies work for human development, New York: UNDP.

Volkow, N. (2000). Strategic Use of Information Technology Requires Knowing how to Use Information, in C. Avgerou and G. Walsham (eds.) Information Technology in Context: studies from the perspective of developing countries, London: Ashgate, pp. 56-69.

Wade, R. (2004). Bridging the Digital Divide: New route to development or new form of dependency?, in C. Avgerou, C. Ciborra and F. Land (eds.) The Social
Study of Information and Communication Technology: Innovation, actions, and contexts, Oxford: Oxford University Press, pp. 185-206.

Walsham, G. (1992). Decentralisation of Information Systems in DC's: Power to the people?, in S.C. Bhatnagar and M. Odedra (eds.) Social Implications of Computers in Developing Countries, New Delhi: Tata McGraw-Hill, pp. 197-208.

Walsham, G. (1993). Interpreting Information Systems in Organizations, Chichester: John Wiley.

Walsham, G. (2001). Making a World of Difference: IT in a Global Context, Chichester: John Wiley.

Walsham, G. (2002). Cross-Cultural Software Production and Use: A structurational analysis, MIS Quarterly 26(4): 359-380.

Walsham, G., Robey, D. and Sahay, S. (2007). Foreword: Special issue on information systems in developing countries, MIS Quarterly 31(2) 317-326.

Walsham, G. and Sahay, S. (2006). Research on Information Systems in Developing Countries: Current landscape and future prospects, Information Technology for Development 12(1): 7-24.

Warschauer, M. (2003). Dissecting the "Digital Divide": A case study in Egypt, The Information Society 19(4): 297-304.

Westrup, C., Liu, W., El Sayed, H. and Al Jaghoub, S. (2003). Taking Culture Seriously: ICTs, cultures and development, in S. Madon and S. Krishna (eds.) The Digital Challenge: Information Technology in the Development Context, Hampshire: Ashgate.

Whitley, E.A., Hosein, I.R., Angell, I.O. and Davies, S. (2007). Reflections on the Academic Policy Analysis Process and the UK Identity Cards Scheme, The Information Society 23(1): 51-58.

World Bank (1999). World Bank Development Report: Knowledge for Development, New York: Oxford University Press.

Wresch, W. (1998). Information Access in Africa: Problems with every channel, The Information Society 14(4): 295-300.

Zakaria, N., Stanton, J.M. and Sarker-Barney, S.T.M. (2003). Designing and Implementing Culturally-Sensitive IT Applications: The interaction of culture values and privacy issues in the Middle East, Information Technology \& People 16(1): 49-75.

Zwicker, R., Souza, C.A. and Vidal, A.G. (2006). An Assessment on the Informatization of Brazilian Industrial Companies, Electronic Journal on Information Systems in Developing Countries 23(1): 1-25.

\section{About the author}

Chrisanthi Avgerou is Professor of Information Systems at the London School of Economics and Political Science. Her main interests concern the relationship of ICT to organizational change and the role of ICT in socio-economic development. She is chairperson of the IFIP Technical Committee 9 on Social Implications of Information Technology and she chaired the IFIP WG 9.4 group on computers in developing countries from 1996 till 2003. Among her recent publications are Information Systems and Global Diversity, and The Social Study of Information and Communication Technology: Innovation, Actors, and Contexts, both published by Oxford University Press. 